\title{
Investigating The Styles Of Teaching And Learning In The RE Curriculum In Botswana Secondary Schools
}

Mutendwahothe Walter Lumadi, North West University, South Africa James Onyango Awino, University of Botswana, South Africa

\begin{abstract}
This is part of a larger study that investigated the impact of democratic pedagogy in the Religious Education (RE) curriculum in Botswana secondary schools. It investigated the teaching and learning styles in the RE curriculum in Botswana secondary schools. This was intended to explore how far the democratic space has been appropriated in the Botswana RE classroom.

The literature review focused on some studies that focused on the need to promote democratic pedagogy in the classroom. The research methodology employed both quantitative and qualitative methods. The data generated for this study, as projected by graphical analysis in Table 1 and Figure 1 , indicate how in most of the 4-minute observation intervals the teacher tallies on the rate of class participation exceeded those of students. This provides evidence that RE teachers tend to restrict participation of learners. RE teachers, therefore, might need to vary their classroom roles from being dominative to emphasize facilitation of more learners' active classroom participation.
\end{abstract}

Keywords: Key words: democratic pedagogy, religious education, authoritarian teaching, informal teaching style, schools.

\section{INTRODUCTION}<smiles>c1ccccc1</smiles>

everal scholars have observed that one of the most striking features of contemporary classrooms is the range and variety of teaching/learning styles, both formal and informal, operating in classrooms (Mycock, 1970; Cohen, Manion \& Morrisson, 2001). For example, Cohen, et al have depicted a formal style as characterized by strict, overt discipline, a high degree of social distance between teachers and students, a 'chalk and talk' type of lesson with little interaction between one student and another, individual work with no talking, an emphasis on book work, the teacher acting as an expert, and so on. On the other hand, they have depicted an informal/democratic style as characterized by a freer discipline, less social distance between students and teachers, experiential and active learning using a variety of resources, children learning in groups, and diagnostic assessment is carried out.

Democratic pedagogy is a much talked about subject today. However, most African schools from researchers' observations have tended to write it off as purely Western capitalist ideology. This article attempts to look at the present teaching and learning styles in Religious Education in Botswana secondary schools to bring out the style that is predominant in them.

\section{OBJECTIVES OF THE STUDY}

This study explored one of the objectives of the research under study. It investigated the styles of teaching and learning in the RE curriculum in Botswana secondary schools. 


\section{LITERATURE REVIEW}

The many studies and reports with regard to the need for Botswana schools to consider shifting from teacher-centred (undemocratic) to learner-centred (democratic) pedagogies have provided a broad framework for the examination of the impact of democratic theory oriented within RE curriculum in Botswana Secondary Schools (Education for Kagisano, 1977; Fuller \& Snyder, 1991; Prophet, 1995; Kehumile, 1996; Tabulawa, 1997 \& 1998; Tafa, 2001; Adeyemi, 2002; Matsetse, 2004; Awino, Mmolai \& Dinama; 2005; Polelo, 2005; Masire, 2006). Most of these studies are further discussed and illuminated in the foregoing review.

Starting with a reformative contribution of the Report of the National Commission on Education (1977: 2326) Education for Kagisano i.e. Education for Social Harmony in Botswana context, it recommended education that has concern for the following: democracy, development, self-reliance, unity and botho.

Amongst the stipulations that have been enumerated here, the first principle aforecited 'democracy' has relevance for reflections on RE pedagogy. It is therefore important to point out further, that the sections 2.09, 2.10 and 2.11 under the sub-heading cited as "Education and Democracy" in the RNCE have a logical augmentation for this study. A look at its general ideas seeks to legitimate democracy in Botswana along the following trends:

In section 2.09, democracy involves giving each mature person a voice in the running of affairs and the chance to participate, directly or through representatives, in decisions affecting his/her life. If democracy is to work, then people must have sufficient information to make wise decisions, and their decisions must be respected.

In section 2.10, the implementation of democracy in education will have several implications. As many decisions as possible must be left to those mostly closely affected by them... the community and parents, professional workers in education, and the pupils themselves....

In section 2.11, the curriculum should include teaching about democratic institutions and the way they work, and education should incorporate practical experiences of democratic institutions through visits to Kgotla, Council or Parliament.

A further overview of some of the aforecited studies can be advanced briefly. Fuller and Snyder (1991: 274) raise a number of unfavourable systemic factors such as large class sizes, examinations-driven curricula, difficult syllabi and absence of adequate learning materials that make it difficult to actualize the learner-centred pedagogy.

In a paper entitled Democracy in Botswana; Challenges and Motivations since 1996; Masire (2006) former President of Botswana observes that participating and inclusive democracy was practised in Botswana. He gives an example of the Kgotla as a system that has a participating system, where everyone is allowed to say his or her opinion so that it could be discussed and the good of it taken advantage of. He argues that leadership functions are decentralised to the smallest section of the community.

Masire (2006) further outlined certain features of democracy available in Botswana today thus:

- $\quad$ Peaceful transition from colonial rule to independence status.

- $\quad$ Regular 5-year elections ever since the attainment of independence.

- $\quad$ Blending of traditional and modern forms of governance institutions and practices.

- Major constitutional developments: amendment of the citizenship Act, introduction of the Independent Electoral Commission and the Limitations of the terms of Office of the President.

- $\quad$ Expansion of representation in the National Assembly; the reduction of voting age from 21 to 18 years; and the evolution of the AU Party Conference.

The features outlined here seem to be supportive of the general idea that the government allows a process of democratic interplay and provides a favourable environment towards democratisation of the Botswana classroom. 
Despite such aforementioned support to democratisation, what happens inside some classrooms are not happy events if we go by findings of certain studies (Fuller \& Snyder, 1990; Prophet \& Rowell, 1990; Chapman, Snyder \& Bucherfield, 1993; Prophet, 1995; Tabulawa, 1997; Tafa, 2001; Tabulawa, 2003; Polelo, 2005; Carney, 2006).

It can be observed that the persistence of student centred classroom discourse in Botswana appears to be fairly well documented going by the foregoing studies. While it can be seen that a number of studies have been done, interpreting the nature of classroom instruction in terms of student or teacher-centeredness, most of these studies have not been specific to RE. But of particular interest for this study are their implications for democratic pedagogy in general.

What would be useful, at this juncture, is taking up a few of these studies for a further discussion to highlight some of the challenges that face Botswana's schools today. Let me take a few examples.

The first example, Prophet (1995: 132) in his study of the Botswana Junior secondary curriculum revealed the following features that were discernible to a greater or lesser degree in all the lessons which were observed as follows:

- $\quad$ The continued teacher dominance of classroom talk.

- A minimum of active engagement/participation of learners.

- $\quad$ A continued dependence on whole class teaching with little evidence of group work.

These findings corroborated earlier evidence which indicated that classroom instruction remained predominantly teacher centred and authoritarian with passive students engaged mainly in recall learning.

While the foregoing findings outlined describe patterns that take place in not only English classrooms but also patterns of instruction observable in Science and Social Studies in Botswana classrooms, the researcher argues that such patterns described here may not be used to draw any conclusions about what takes place in RE classrooms since the findings are not from RE classrooms. So this research intends to play an important role in revealing patterns that take place in the RE classroom in Botswana secondary schools.

A second example is a study carried by Tabulawa (1997: 199). He did this in a school in Botswana consisting of a student population of 1300 and staff membership of 73 in order to study the classroom practice or process. The questionnaires were administered to 816 geography students, 7 teachers and 10 parents were interviewed. His findings revealed the following classroom features:

- $\quad$ Little student-student and student-teacher interaction.

- $\quad$ Teacher-centred Geography teaching and learning.

- $\quad$ Teachers and their students devised strategies maintaining the knowledge provider-receiver relationship.

The study identified some factors associated with the didactic and authoritarian classroom practice in Botswana schools thus:

- $\quad$ The imported bureaucratic-authoritarian model of nineteenth century Britain.

- $\quad$ The missionary/colonialists belief in the supremacy of the Western culture.

- $\quad$ The authoritarianism inherent in Tswana society and

- The human resource development policy of post-independence Botswana. (Tabulawa, 1997: 203).

Such developments provide an impetus to find out what goes on in RE classroom in terms of partaking in classroom democratic processes.

A third is a study entitled "Pedagogical Styles and Paradigms: Towards an analytical framework for understanding classroom practice in Botswana" (Tabulawa, 1998: 3). In this study, he has posited a psychic fixation 
in which he argues that to expect teachers to shift from the known pedagogical paradigm (i.e. transmission-reception pedagogical style) which inform their world is not an easy thing. Tabulawa's foregoing premise is interpreted by the researcher to mean that people are usually resistant and afraid of change. The idea of change can entail moving out of what is comfortable, known and often easy i.e. maintaining an already usual practice of a teacher centred pedagogy may be an easier position. It is therefore necessary to find out what position RE teachers maintain.

A fourth example is that of a study by Tafa (2001: 11ff). This study investigated the impact of school and classroom life on the teaching perceptions and practices of newly qualified teachers during their first four months working in Botswana Junior secondary Schools. Data was collected from five case study schools and two secondary colleges of education that trained the teachers. Document analysis, school and classroom observations, interviews and supplementary questionnaires were employed.

The findings revealed the idea that colleges are liberal and progressive while schools are conservative and authoritarian. Document analysis of the teacher training model indicates that schools and colleges are essentially partners in the mystification of teaching which is underpinned by a technical rationality model. The study suggested that the root cause of the pervasive transmission method of teaching found in Botswana Junior Secondary schools lies in the behaviourist teacher training model.

The fifth example, Tabulawa (2003: 7ff) in his study on 'International Aid Agencies, Learner-centred Pedagogy and Political Democratisation' argues that learner-centeredness is a political and ideological scheme to transform human relations even though it is encapsulated in a value-free educational terms. He further explains that since the collapse of the Berlin Wall and arrival of the new world order (neo-liberal ideology), democratisation became a buzzword and for the developed world evidence of political democratisation became a conditionality for obtaining overseas aid from the developed North especially the IMF and World Bank. Such comments tend to reflect the various forces at play behind the need to foster democratic curriculum. The researcher believes that these forces also needed new reforms in the classroom to shape a mind of students that can live beyond the classroom. Tabulawa (2009: 93) further observes how Botswana, as a liberal democracy, has endeavoured over the years to use formal education to entrench a democratic ethos. He gives some of the developments in the 1980s such as the Primary Education Improvement Project (PEIP) and the Junior Secondary Improvement Project (JSIP) Botswana embarked upon which heavily emphasised learner-centred pedagogy.

The sixth example is that of the study by Polelo (2005). This study included 289 children from 10 schools, 48 teachers, 96 parents and 8 boarding staff. Using interviews and examining statistical records and other administrative documents, the researcher indicated that the use of corporal punishment in RADS schools reflects the relationship between teachers and pupils. The findings also indicated that the classroom observations reveal that most teaching is teacher-centred. Polelo (2005: 296) observed: "In the primary schools, it is punctuated by recitations and rote learning, such relations push out RADS pupils whose culture is neither domineering nor accommodative to corporal punishment."

\section{METHODOLOGY}

The study employed quantitative and qualitative methods. Multiple approaches were preferred owing to the fact that they provide not only insight, broad understanding and different prepositions (Woods, 1992; Bogdan \& Biklen, 1998: 71; Creswell, : 2002: 61) but also offer objective evaluation in which the observer manipulates and observes social or human situation in a dispassionate manner (Creswell, 1994: 2; Neuman, 2000: 261 and Mertens, 2003: 9).It can further be noted that the field worker makes a claim to moral and empirical authority in which a researcher shows that the world of real lived experience can still be captured (Denzin \& Lincoln, 2003: 27).

Bogdan and Biklen (1998: 71) explains the qualitative tradition in attempting to capture the subjects' own words and letting the analysis emerge, allow for open-minded responses and are flexible enough for the observer to note and collect information on unexpected aspects of the topic such as interview and observation guides.

From the above submissions the value of a variety of methods can be seen. The design of the study made use of questionnaires, classroom instructional observation and an interview schedule. The study recognized the 
importance of triangulation. That is why the study adopted the use of both quantitative and qualitative research designs as a means of triangulation for convergence purposes (Mathison, 1988: 55-59).

The researcher conducted observation using self- designed instrument on forty-two (42) respondents picked through convenient sampling from the twenty four (24) schools from three regions earmarked for the study. In each region therefore a total of fourteen respondents were represented. They were observed once within a period of five months. The lessons observed were for 40 minutes. However, the lessons ended 30 minutes to give allowance for pupils' transition to the next class.

The observation schedules were self-designed to gauge the patterns of teaching/learning styles, whether teacher or learner-cantered. This observation schedule catered for observation and recording of the RE teaching/learning patterns within 36 minutes at four- minute intervals.

\section{RESULTS}

The research question was addressed by the Classroom Observation Schedule, which helped in obtaining teacher and learner-centred tallies as indicated in Table 1 and Figure 1, one open-ended question and one interview question, as provided in the foregoing discussion.

Table 1: Styles of Teaching and Learning, Teacher-Centred vs. Learner-Centred $\mathrm{N}=42$

\begin{tabular}{|c|c|c|c|c|}
\hline Time & Teacher-Centred Tallies & $\mathbf{\%}$ & Learner-Centred Tallies & \% \\
\hline 4 & 38 & 90.5 & 4 & 9.5 \\
\hline 8 & 34 & 81 & 8 & 19 \\
\hline 12 & 22 & 53.4 & 20 & 47.6 \\
\hline 16 & 25 & 56.2 & 21 & 44.8 \\
\hline 20 & 21 & 50 & 14 & 50 \\
\hline 24 & 28 & 66.7 & 21 & 33.3 \\
\hline 28 & 21 & 50 & 16 & 50 \\
\hline 32 & 26 & 61.9 & 10 & 38.1 \\
\hline 36 & 32 & 73.9 & 26.1 \\
\hline
\end{tabular}

Figure 1 reveals that in most of the nine 4-minute observation intervals teacher tallies exceeded $50 \%$, except for learner centered tallies where most of the tallies are below $50 \%$.

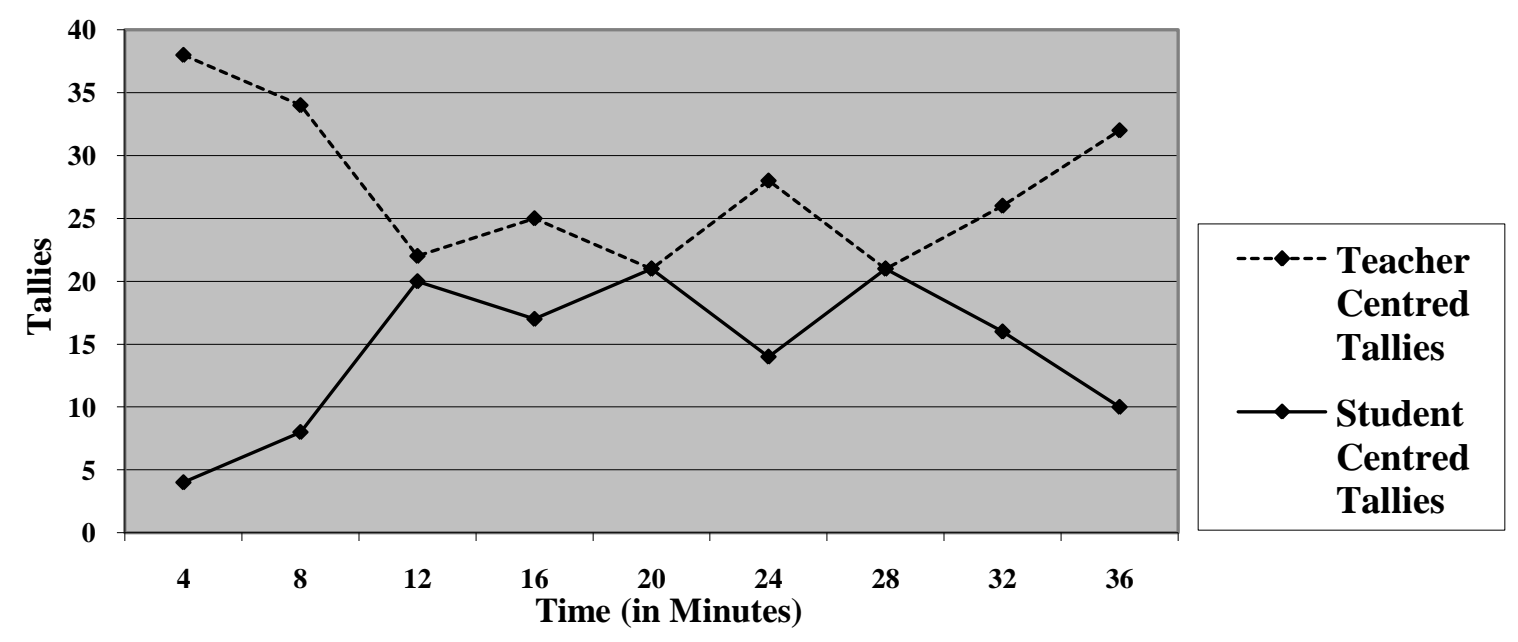

Figure 1: Patterns of Teaching and Learning Styles 
During each session the 4-minute segments of classroom interaction were ticked or scored once on each segment. This depended on who takes a large amount of time, whether the teacher or the learner after 4 minutes. In other words, the observer analyses the proportion of teacher talk and learner talk and scores it once after a 4-minute interval.

In Figure 1, the teacher centred tallies and learner centred tallies were subjected to a graphical comparison using a two-dimensional chart (line-chart). This line chart format was found particularly useful and relevant in depicting dynamic relationships in classroom teaching and learning styles. It can be seen in Figure 1 that the graph constructed has the $\mathrm{x}$-axis representing time (in minutes) and y-axis representing values of the variables (tallies). The teacher and learner centred tallies have been made distinctive by dotted and continuous lines respectively.

The result suggests that the teacher still takes a centre stage in the classroom as seen from the tabular projection (Table 1) and graphical analysis depicted in Figure 1. What is noticeable is that teacher-centred tallies are more dominant than learner-centred tallies.

Furthermore, the findings in Table 1 suggest that learners are given very little time at the start of the session (9.5\%) and even at the tail end of the session (26.1\%). A similar trend is shown in the graphical form. This could be an indicator that not much is done yet in RE teaching and learning sessions to accord learning opportunities for more classroom engagement in order to fix a democratic culture in the classroom.

As can be seen, the results here concur with most of those made in the review of related literature. Literature reviewed that teachers tend to be stuck in their known and comfortable paradigm or behaviourist groove that seem to remain predominantly teacher-centred and authoritarian with passive students mainly in recall learning category (Prophet \& Rowell, 1990; Fuller \& Snyder, 1991; Tabulawa, 1997; Tafa, 2001 and Polelo, 2005).

The open-ended question asked on whether they think the current pattern of teaching and learning of RE is closed or not gave indications that the current pattern of teaching and learning in the RE curriculum in Secondary Schools appear closed. Sometimes few respondents (4\%) pointed to a view that it is open. Such divergent views are worth probing into to know clearly what is happening in Botswana RE context. For example, the following are responses of some of the sampled teachers to the open ended question on reasons for the answers:

Respondent 1: The inclusivity of the Junior Secondary RE is a sign of a democratic or open syllabus. But at the same time I feel that the learners experience in the present teaching and learning situation is not taken into consideration. This can be a hindrance to democratization of RE.

Respondent 2: Teachers do everything for students and learners have less say in the RE classroom.

Respondent 3: There are boundaries to the religions studied. For instance, students only study religions that are registered in Botswana. The content is restricted to some religions.

Respondent 4: In senior secondary school mainly one religion is taught and students are expected to provide what is provided in the recommended textbooks.

The respondents were asked to state the dominant method of classroom teaching and learning. Of these respondents $86 \%$ of them indicated that the pattern of teaching and learning of RE in Botswana Schools is rather closed. Below are examples of some of their responses:

- The subject RE itself is teacher-centred and does not allow students to contribute any ideas outside the prescribed textbooks.

- $\quad$ Learners still have no much role given them in class and teachers do a lot of teaching.

- $\quad$ Teachers prefer lecture method of teaching. 


\section{CONCLUDING REMARKS}

The results, as depicted in Table 1 and Figure 1 (graphical analysis), provide evidence that RE teachers restrict learners' participation in the classroom.

Flanders (1970: 198) review of the literature has provided tips on how to be a successful teacher by improving patterns of teaching and learning styles as follows:

- $\quad$ Successful teachers vary their classroom roles from dominative to supportive ones and should be able to secure pupil' compliance and initiative as the situation demands.

- $\quad$ Successful teachers should be able to switch at will from one role to another and not blindly follow a single approach to the exclusion of others.

- $\quad$ Successful teachers are more able to move from their diagnosis of a classroom problem to a follow up course of action.

- $\quad$ They are both critical of their classroom pupils' and sensitive to their needs as human beings.

Furthermore, he suggests that successful teachers should be flexible in their teaching styles and should shift easily and naturally from the direct to the indirect, from being critical observers to sympathetic counsellors, depending on the need. He further noted that when pupils' ideas are incorporated into the learning activities, they seem to learn more and also develop more positive attitudes toward the teacher and the learning situation; and that teachers who are overly critical in class appear consistently to achieve less in most subject areas. This review has some relevance for RE teachers in clarifying what teachers can use to be successful in RE curriculum orientations.

\section{AUTHOR BIOGRAPHIES}

Professor M. W. Lumadi is an experienced Curriculum Developer. He has worked at numerous Higher Education and Training institutions in South Africa, such as Westminster College of Education (as Rector), South African College for Teacher Education in Pretoria, University of Venda for Science and Technology, Kingdom International College (as dean), and, currently, North West University (NWU). Since 2003, he has served at various managerial committees in NWU and is currently director of the School of Postgraduate Studies. He is a member of Campus and Institutional Senate, Chairperson of Research, Commissioner of Oath, and Member of Council. Professor Lumadi is also an external examiner for Limpopo, Free State, Johannesburg, Tswane University of Technology, University of South Africa, Walter Sisulu, and Zululand.

James O. Awino is a Senior Lecturer in the Department of Languages and Social Sciences Education'. He studied for his $\mathrm{PhD}$ in Curriculum at the North West University, South Africa. His areas of teaching/research include Curriculum Studies, Philosophy of Education, Educational Administration, Religious Education and English education. He has contributed to scholarly journals both within and outside Kenya.

\section{REFERENCES}

1. Adeyemi, M. B. (2002). An investigation into the status of Teaching and Learning of the concept of Democracy at the Junior Secondary School Level in Botswana. Educational Studies, 28 (4), $385-401$.

2. Awino, J. O.; Mmolai, S. K. and Dinama, B. (2005) Community Based Methodology in RE: Towards Realisation of Vision 2016. Journal of Sociology and Education in Africa, 4 (2), 193-207.

3. Bogdan, R. C. and Biklen, S. K. (1998) Qualitative Research in Education: An Introduction to Theory and Methods. Boston: Allyn and Bacon.

4. Carney, S. (2006) University Governance in Denmark: from democracy to accountability? European Educational Research Journal, 5 (3 \& 4), 234-243.

5. Chapman, D. W., Snyder, C. W. and Bucherfield, S. A. (1993) Teacher Incentives in the Third World. Teaching and Teacher Education, 9, 301-306.

6. Cohen, L.; Manion, L and Morrison, K (2001) A guide to teaching practice. $4^{\text {th }}$ Edition London: Routledge $\&$ Falmer. 
7. Creswell, J. W. (2002) Educational research: Planning, conducting and evaluating quantitative and qualitative research. Upper Saddler River: Columbus.

8. Creswell, J. W. (1994) Research Design: Quantitative and Qualitative Approaches. London: Sage Publications.

9. Denzin, N. Lincoln, Y. S. (Eds) (2003) Strategies of Qualitative Inquiry. London: Sage Publications.

10. Education for Kagisano (1977) Report of the National Commission on Education. Government Printer: Gaborone.

11. Flanders, N. A. (1970) Analyzing Teaching Behaviour. MA: Addison - Wesley.

12. Fuller, B. and Snyder, C. W. (1991) Vocal Teachers, Silent Pupils Life in Botswana Classrooms. Comparative Education Review, 35, 274-293.

13. Fuller, B. and Snyder, C. W. (1990) Colourful Variation in teaching practices? In Curriculum in the Classroom (edited by Snyder, C. W. and Ramatsui, P. T.). MacMillan: Gaborone.

14. Hargreaves, D. H.(1973) Interpersonal relations and Education. London: Routledge \& Kegan Paul.

15. Kehumile, K. M. (1996) An Analysis of the Methods and Activities in the Teaching of Religious Education in Gaborone City and Southern District Primary Schools ofBotswana in the Post-Colonial era. Unpublished Med. Thesis. Gaborone: University of Botswana.

16. Masire, K. (2006) Democracy in Botswana: Challenges and Motivations since 1966. A paper presented at the University of Botswana to Academic and Support Staff. Gaborone: University of Botswana.

17. $\quad$ Mathison, S. (1988) 'Why Triangulate?' Educational Research. 17 (2), 55 - 59.

18. Matsetse, M. (2004) The Impact of Teachers' Religious Commitment on the teaching and Learning of Religious Education in Botswana Primary Schools. Unpublished MEd thesis. Gaborone: University of Botswana.

19. Mertens, D. M. (2003) Research Methods in Education and Psychology. London: Sage Publications.

20. Mycock, M. A. (1990) Vertical grouping in the primary school in Rogers V. R. (ed). Teaching in the British Primary School. London: MacMillan.

21. Neuman, W. L. (2000) Social Research methods: Quantitative and Qualitative Approaches. Boston: Allyn and Bacon.

22. Polelo, M. M. (2005) Inside Undemocratic Schools: Corporal Punishment and Physical Abuse in Botswana Schools. In A. A. Adeyinka and J. B. Babalola. Journal of Education in Africa, 4 (2), 277-300.

23. Prophet, R. B. (1995) Views from the Botswana Secondary Classroom: Case Study of Curriculum Intervention. International Journal of Curriculum Development, 15 (2), 127-140.

24. Prophet, R. B. and Rowell, P. M. (1990) The Curriculum Observed. In Snyder, C. W., Ramatsui, P. T. (eds) Curriculum in the Classroom. Gaborone: MacMillan.

25. Republic of Botswana (1977) Report of the National Commission on Education. Gaborone: Government Printer.

26. Tabulawa, R. (1997) Pedagogical Classroom Practice and the Social Context: the Case of Botswana. International Journal of Educational Development, 17 (2), 189-204.

27. Tabulawa, R. (1998) Pedagogical Styles as Paradigms: Towards an Analytical Framework for Understanding Classroom Practice in Botswana. Mosenodi: Journal of the Botswana Educational Research Association, 6 (1), 3-15.

28. Tabulawa, R. (2003) International Aid Agencies, Learner-Centred Pedagogy and Political Democratisation: a Critique. Comparative Education, 39 (1), 7-26.

29. Tabulawa, R. (2009) Education Reform in Botswana. Reflections on Policy Contradictions and Paradoxes. Comparative Education. 45 (1), 87-107.

30. Tafa, E. M. (2001) Stuck in the Behaviourist Groove: The Behaviourist Teacher Training Model and School Authoritarianism in Botswana. Mosenodi: Journal of the Botswana Educational Research Association, 9 (2), 11-24.

31. Woods, A. G. (1992) International Early Childhood and Education; Historical Perspectives. International Handbook of Early Childhood Education. New York: Garland Publishing. 